\title{
A Composite of Functional Status and Pneumonia Severity Index Improves the Prediction of Pneumonia Mortality in Older Patients
}

\author{
Francisco Sanz, MD, $P h D^{7}$, María Morales-Suárez-Varela, MD, PhD ${ }^{2,3}$, Estrella Fernández, MD, PhD ${ }^{7}$, \\ Luis Force, MD, $P h D^{4}$, María José Pérez-Lozano, MD, PhD ${ }^{5}$, Vicente Martín, MD, PhD \\ Mikel Egurrola, $M D, P h D^{7}$, Jesús Castilla, $M D, P h D^{3,8}$, Jenaro Astray, $M D, P h D^{9}$, \\ Diana Toledo, MD, PhD 3,10 , and Ángela Domínguez, MD, PhD ${ }^{3,10}$ Project Pl12/02079 Working Group
}

\begin{abstract}
${ }^{1}$ Consorci Hospital General Universitari de València, València, Spain; ${ }^{2}$ Universitat de València, València, Spain; ${ }^{3}$ ClBER Epidemiología y Salud Pública (CIBERESP), Madrid, Spain; ${ }^{4}$ Hospital de Mataró, Mataró, Spain; ${ }^{5}$ Hospital Universitario Virgen de Valme, Sevilla, Spain; ${ }^{6}$ Universidad de León, León, Spain; ${ }^{7}$ Hospital de Galdakao, Usansolo, Spain; ${ }^{8}$ Instituto de Salud Pública de Navarra, IdiSNA, Pamplona, Spain; ${ }^{9}$ Consejería de Sanidad, Madrid, Spain; ${ }^{10}$ Departament de Salut Pública, Universitat de Barcelona, Barcelona, Spain.
\end{abstract}

\begin{abstract}
BACKGROUND: The baseline health status may be a determinant of interest in the evolution of pneumonia.

OBJECTIVE: Our objective was to assess the predictive ability of community-acquired pneumonia (CAP) mortality by combining the Barthel Index (BI) and Pneumonia Severity Index (PSI) in patients aged $\geq 65$ years.

DESIGN, PATIENTS AND MAIN MEASURES: In this prospective, observational, multicenter analysis of comorbidities, the clinical data, additional examinations and severity of CAP were measured by the PSI and functional status by the BI. Two multivariable models were generated: Model 1 including the PSI and BI and model 2 with PSI plus BI stratified categorically.
\end{abstract}

KEY RESULTS: The total population was 1919 patients, of whom $61 \%$ had severe pneumonia (PSI IV-V) and $40.4 \%$ had some degree of dependence (BI $\leq 90$ points). Mortality in the PSI V-IV group was $12.5 \%$. Some degree of dependence was associated with increased mortality in both the mild $(7.2 \%$ vs. $3.2 \% ; \mathrm{p}=0.016)$ and severe $(14 \%$ vs. $3.3 \%$; $<<0.001)$ pneumonia groups. The combination of PSI IV-V and BI $\leq 90$ was the greatest risk factor for mortality (aOR 4.17; 95\% CI 2.48 to 7.02 ) in our series.

CONCLUSIONS: The use of a bimodal model to assess CAP mortality (PSI + BI) provides more accurate prognostic information than the use of each index separately.

KEY WORDS: functional status; community-acquired pneumonia; severity assessment.

$J$ Gen Intern Med 33(4):437-44

DOI: $10.1007 / \mathrm{s} 11606-017-4267-8$

(c) Society of General Internal Medicine 2017

\section{INTRODUCTION}

Community-acquired pneumonia (CAP) causes high mortality and morbidity worldwide. The incidence increases with age and is estimated at 3.1/1000 inhabitants/year in patients aged $\geq$ 65 years, with a mortality rate of $10-25 \% .{ }^{1,2} \mathrm{CAP}$ in elderly

Received June 28, 2017

Revised September 29, 2017

Accepted December 4, 2017

Published online January 4, 2018 patients is a destabilizing factor for baseline comorbidities and results in a slower recovery and major burden for caregivers as well as considerable economic costs. ${ }^{3,4}$

Scales that assess the severity of CAP [Pneumonia Severity Index (PSI), CURB-65] are of great utility for prognostic evaluations and determining the level and intensity of care required. ${ }^{5,6}$ However, although these scales work well in clinical practice, there are other intrinsic factors in elderly patients that are determinants of the outcomes but are not included in the scales. The previous quality of life is a decisive prognostic factor, especially in institutionalized patients. ${ }^{7}$ The functional status has been independently associated with the outcome of CAP and a worse prognosis. ${ }^{8,9}$ The incidence of emergency room visits in the elderly due to CAP increases in tandem with a worse functional status. ${ }^{10}$ In addition, CAP in the elderly may have some hidden clinical manifestations that can delay the diagnosis and the administration of antibiotic treatment, and it may have clearly unfavorable prognostic consequences. ${ }^{11,12}$

The baseline functional status is a determinant of immediate and long-term survival after CAP. It is estimated that $60 \%$ of patients with multiple dependency will die during the first 12 months and only $25 \%$ will survive for $\geq 2$ years. ${ }^{13}$

Identification of the risk of complications or mortality is crucial since it involves specific prognostic and ethical implications such as the introduction or interruption of some therapeutic measures. ${ }^{14}$ Moreover, the effectiveness of preventive measures against respiratory infections in the elderly can be influenced by the baseline status, with a decrease in the effectiveness of the influenza vaccine observed in patients with poor functional status. ${ }^{15}$

There is growing evidence that the functional status, measured by the Barthel Index (BI), is more important than age and comorbidity in predicting prognosis at 12 months in the elderly. ${ }^{16}$ Even small changes in the BI are associated with clinically relevant outcomes. ${ }^{16}$ In CAP, a worse BI is directly related to increased costs, hospital length of stay and mortality. ${ }^{17}$ The BI showed a very good correlation between the degree of functional impairment and survival of elderly 
patients admitted to an acute geriatric unit. ${ }^{18}$ A recent study has reported that, in patients of different ages diagnosed with $\mathrm{CAP}$ with a $\mathrm{BI} \leq 80$, mortality was four times greater than in the general population. ${ }^{19}$

Identification of severity and the risk of death in elderly patients with CAP is a challenge for clinicians because many patients have associated comorbidities and other situations that affect their baseline health and cannot be assessed by conventional pneumonia severity scales. ${ }^{20}$ Therefore, accurate management of CAP in this population requires a holistic approach, taking the functional status into account in addition to the assessment of disease severity. The association between increased mortality in CAP patients with a worse functional status suggests that the addition of functional indexes to prognostic scales could improve the identification of adverse outcomes and provide data to improve clinical care.

The objective of this study was to assess the predictive power of a composite index combining the BI and PSI in assessing mortality in non-institutionalized patients with CAP aged $\geq 65$ years.

\section{MATERIAL AND METHODS}

\section{Study Design. Inclusion and Exclusion Criteria}

We conducted an observational, prospective, multicenter study involving 20 hospitals from seven Spanish regions in 2013-2015. The enrollment was prospective. Patients admitted to the hospital for pneumonia were asked to participate in the study if they met the inclusion criteria.

Inclusion criteria were a diagnosis of CAP requiring hospitalization for $\geq 24 \mathrm{~h}$ in patients aged $\geq 65$ years. Pneumonia was defined as an acute clinical picture with $\geq 1$ of the following symptoms: fever, dyspnea, cough, sputum, chest pain and new onset of alveolar infiltration on chest $\mathrm{x}$-ray. ${ }^{21}$

Patients aged $\leq 64$ years, institutionalized patients and those with nosocomial pneumonia, defined as pneumonia occurring $\leq 48 \mathrm{~h}$ after hospital admission or within the first 14 days after discharge, were excluded.

Patients were consecutively approached for enrollment and were offered verbal and written information. Signed informed consent was required to be included in the study.

\section{Variables Analyzed}

Baseline variables were collected within the first $24 \mathrm{~h}$ after hospital admission. The following variables were collected: age, sex, smoking status, alcohol intake $>80 \mathrm{~g} /$ day and social support. Comorbidities analyzed included chronic obstructive pulmonary disease (COPD), defined as a current or past history of smoking (> 20 pack-years), clinical evaluation and lung function tests with an obstructive pattern (FEV1/FVC $<70$ ). Histories of renal failure, heart failure, cerebrovascular disease, dementia, diabetes mellitus, chronic liver diseases (viral, toxic liver or cirrhosis) and neoplasia were collected.
Factors collected in association with immunosuppression included HIV infection, hematologic malignancy resulting in impairment of humoral or cellular immunity, chemotherapy during the 4 weeks before the diagnosis of CAP, prolonged corticosteroid therapy (> $20 \mathrm{mg}$ prednisone/day for at least 3 weeks) and solid organ transplantation. Information on the vaccination status (pneumococcal and influenza) and the duration of symptoms before diagnosis was recorded.

\section{Assessment of Functional Status}

The BI is a clinical tool that evaluates the ability to perform basic activities of daily living and assigns a score depending on the degree of dependence. ${ }^{22}$ Activities assessed include autonomy in feeding, moving, climbing stairs, dressing, using the toilet and continence. The score ranges from 0 (total dependence) to 100 (complete autonomy). The Barthel Index (BI) was used to assess the functional status 4 weeks prior to admission for pneumonia. Since this was a multicenter study all researchers had the same version of the BI test. When the patient had cognitive deterioration or confusion, then information was obtained from the main carer, family or nursing staff. A cutoff of $\mathrm{BI} \leq 90$ was used to define some degree of dependency.

\section{Assessment of Severity}

The severity of CAP was assessed using the PSI, which is based on demographics, comorbidities, physical examination and radiologic and laboratory data at the diagnosis of pneumonia. ${ }^{5}$ According to the risk of death at 30 days, patients were classified as low or moderate risk (PSI I-III) or high or severe risk (PSI IV-V).

\section{Composite Index}

To evaluate the prognostic value, we constructed an index that dichotomously combined the presence of severe pneumonia (PSI IV-V) and the existence of some degree of dependency: PSI IV-V + BI $\leq 90$.

\section{Outcomes}

The primary outcome was 30-day mortality after the diagnosis of CAP.

Other adverse outcomes, such as prolonged length of stay (defined as a stay above the 75th percentile of days of stay in the series), readmission in the first 30 days after discharge, intensive care unit (ICU) admission, the use of vasopressors, requirement for invasive or non-invasive ventilation (IMV/ NIV) and the development of pleural empyema, were assessed.

\section{Ethical Aspects}

Data were treated confidentially by strictly applying Spanish and European legislation. Written informed consent was 


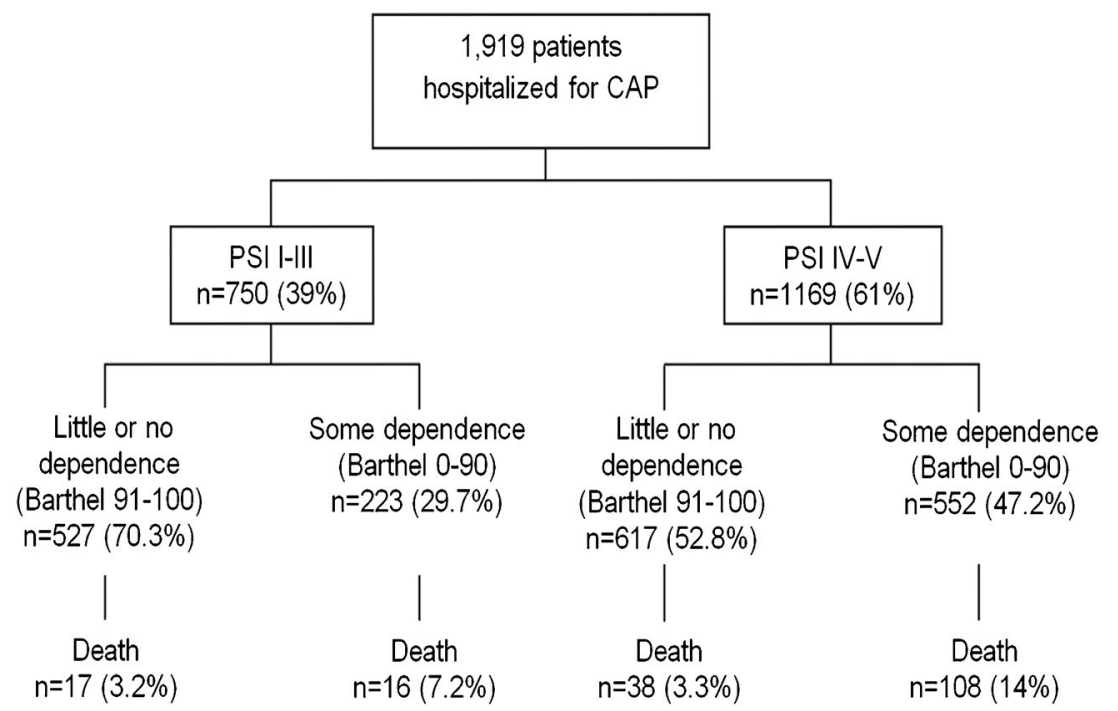

Figure 1 Patient distribution according to pneumonia severity (Pneumonia Severity Index) and level of dependence (Barthel Index).

obtained from all participants. The study was approved by the ethics committees of all participating hospitals (Hospital Clínic of Barcelona Clinical Research Ethics Committee; University Hospital Mutua de Terrassa Clinical Research Ethics Committee; Health Corporacion Parc Taulí of Sabadell Clinical Research Ethics Committee; Clinical Research Ethics
Committee of the Hospital of Mataró, Maresme Consorci Sanitari; Clinical Research Ethics Committee of the Catalan Fundació Unio Hospitals, University Hospital of Barcelona Vall d'Hebrón Clinical Research Ethics Committee, Clinical Research Ethics Committee of the Basque Country; Clinical Health Area of Burgos and Soria Clinical Research Ethics

Table 1 Patient Characteristics According to Degree of Dependence

\begin{tabular}{|c|c|c|c|c|}
\hline & Barthel $>90(n=1144)$ & Barthel $\leq 90(n=775)$ & Unadjusted OR 95\% CI & p value \\
\hline \multicolumn{5}{|l|}{ Demographics } \\
\hline Mean age & 76.5 (SD: 6.8) & 81.9 (SD: 7.1) & - & $<0.001$ \\
\hline Males & $772(67.5)$ & 395 & $0.50(0.42-0.60)$ & $<0.001$ \\
\hline Social support (lives alone) & $243(21.2)$ & $101(13)$ & $0.56(0.43-0.72)$ & $<0.001$ \\
\hline \multicolumn{5}{|l|}{ Comorbid conditions } \\
\hline Smoking & $127(11.1)$ & $41(5.3)$ & $0.45(0.31-0.64)$ & $<0.001$ \\
\hline Alcohol abuse & $276(24.1)$ & $97(12.5)$ & $0.45(0.35-0.58)$ & $<0.001$ \\
\hline COPD & $377(33)$ & $211(27.2)$ & $0.76(0.62-0.93)$ & 0.008 \\
\hline Diabetes mellitus & $358(31.3)$ & $287(37)$ & $1.29(1.07-1.57)$ & 0.009 \\
\hline Chronic renal failure & $184(16.1)$ & $211(27.2)$ & $1.95(1.56-2.44)$ & $<0.001$ \\
\hline Malignancy & $204(17.8)$ & $133(17.2)$ & $1.05(0.82-1.33)$ & 0.705 \\
\hline Chronic liver disease & $52(4.59$ & $23(3)$ & $0.64(0.39-1.06)$ & 0.080 \\
\hline Cerebrovascular disease & $39(3.4)$ & $119(15.4)$ & $5.14(3.54-7.47)$ & $<0.001$ \\
\hline Dementia & $46(4)$ & 183 (23.6) & $7.34(5.26-10.35)$ & $<0.001$ \\
\hline Chronic heart disease & $254(22.2)$ & $277(35.7)$ & $1.95(1.59-2.39)$ & $<0.001$ \\
\hline Immunosuppression & $99(8.7)$ & $76(9.8)$ & $1.15(0.84-1.57)$ & 0.389 \\
\hline Influenza vaccination & $543(47.5)$ & $262(46.7)$ & $1.03(0.86-1.24)$ & 0.745 \\
\hline Pneumococcal vaccination & $550(48.1)$ & $378(48.8)$ & $1.03(0.86-1.23)$ & 0.764 \\
\hline \multicolumn{5}{|l|}{ Clinical data } \\
\hline Duration of symptoms & 5.9 (SD: 11.1) & 5.4 (SD: 7.2) & - & 0.175 \\
\hline PSI IV-V & $617(53.9)$ & $552(71.2)$ & $2.11(1.74-2.57)$ & $<0.001$ \\
\hline \multicolumn{5}{|l|}{ Microbiology } \\
\hline Etiologil diagnosis & $285(24.9)$ & $188(24.3)$ & $0.97(0.78-1.19)$ & 0.744 \\
\hline Pneumococcal etiology & $187(20.8)$ & $111(20.1)$ & $0.96(0.74-1.24)$ & 0.739 \\
\hline Bacteremia & $60(9.9)$ & $53(13.7)$ & $1.44(0.97-2.13)$ & 0.069 \\
\hline \multicolumn{5}{|l|}{ Evolution } \\
\hline Length of stay & 9.7 (SD: 9.5) & 11.8 (SD: 10$)$ & - & $<0.001$ \\
\hline Prolonged LOS (LOS > 75thP) & $223(19.5)$ & $237(30.5)$ & $1.72(1.39-2.13)$ & $<0.001$ \\
\hline Readmission (30 days) & $143(12.5)$ & $121(15.6)$ & $1.29(0.99-1.68)$ & 0.052 \\
\hline ICU admission & $56(4.9)$ & $25(3.2)$ & $0.65(0.40-1.05)$ & 0.074 \\
\hline Vasopressors use & $58(5.2)$ & $82(10.7)$ & $2.22(1.56-3.14)$ & $<0.001$ \\
\hline NIV/IMV & $169(14.7)$ & $147(18.9)$ & $1.74(0.58-2.20)$ & 0.317 \\
\hline Empyema & $28(2.4)$ & $20(2.6)$ & $0.95(0.59-1.70)$ & 0.868 \\
\hline Mortality & $38(3.3)$ & $108(14)$ & $4.71(3.22-6.91)$ & $<0.001$ \\
\hline
\end{tabular}

COPD: chronic obstructive pulmonary disease. LOS: length of stay. ICU: intensive care unit. IMV: invasive mechanical ventilation. NIV: non-invasive ventilation. 75 thP: 75 th percentile 
Table 2 Characteristics of Patients with Severe Pneumonia (PSI IV-V) by Degree of Dependence

\begin{tabular}{|c|c|c|c|c|}
\hline & $\begin{array}{l}\text { PSI IV-V and Barthel } \\
>90(n=617)\end{array}$ & $\begin{array}{l}\text { PSI IV-V and Barthel } \\
\leq 90(\mathrm{n}=552)\end{array}$ & Unadjusted OR 95\% CI & p value \\
\hline \multicolumn{5}{|l|}{ Demographics } \\
\hline Mean age & 77.8 (SD: 6.9) & 82.8 (SD: 7) & - & $<0.001$ \\
\hline Males & $450(72.9)$ & $302(54.7)$ & $0.45(0.35-0.57)$ & $<0.001$ \\
\hline Social support (lives alone) & $134(21.7)$ & $74(13.4)$ & $0.56(0.41-0.76)$ & $<0.001$ \\
\hline \multicolumn{5}{|l|}{ Comorbid conditions } \\
\hline Smoking & $68(11)$ & $24(4.3)$ & $0.37(0.23-0.59)$ & $<0.001$ \\
\hline Alcohol abuse & $149(24.1)$ & $70(12.7)$ & $0.46(0.33-0.62)$ & $<0.001$ \\
\hline COPD & $217(35.2)$ & $156(28.3)$ & $1.37(1.07-1.76)$ & 0.011 \\
\hline Diabetes mellitus & 189 (30.6) & $203(36.8)$ & $1.32(1.03-1.68)$ & 0.026 \\
\hline Chronic renal failure & $123(19.9)$ & $163(29.5)$ & $1.68(1.29-2.20)$ & $<0.001$ \\
\hline Malignancy & $149(24.1)$ & $103(18.7)$ & $1.38(1.05-1.84)$ & 0.023 \\
\hline Chronic liver disease & $32(5.2)$ & $21(3.8)$ & $0.72(0.41-1.27)$ & 0.257 \\
\hline Cerebrovascular disease & $24(3.9)$ & $91(16.5)$ & $4.88(3.06-7.78)$ & $<0.001$ \\
\hline Dementia & $26(4.2)$ & $137(24.8)$ & $7.50(4.84-11.62)$ & $<0.001$ \\
\hline Chronic heart disease & $156(25.3)$ & 219 (39.7) & $1.94(1.51-2.49)$ & $<0.001$ \\
\hline Immunosuppression & $60(9.7)$ & $57(10.3)$ & $1.07(0.73-1.57)$ & 0.732 \\
\hline Influenza vaccination & $313(50.7)$ & $264(47.8)$ & $1.12(0.89-1.41)$ & 0.322 \\
\hline Pneumococcal vaccination & $315(51.1)$ & $277(50.2)$ & $1.04(0.82-1.30)$ & 0.766 \\
\hline \multicolumn{5}{|l|}{ Clinical data } \\
\hline Duration of symptoms & 6 (SD: 13.4) & 5.3 (SD: 7.2) & - & 0.280 \\
\hline \multicolumn{5}{|l|}{ Microbiology } \\
\hline Etiologic diagnosis & $175(28.4)$ & $140(25.4)$ & $0.86(0.66-1.11)$ & 0.248 \\
\hline Pneumococcal etiology & $118(24.2)$ & $85(21.7)$ & $0.87(0.63-1.199$ & 0.382 \\
\hline Bacteremia & $43(13.2)$ & $46(16)$ & $1.25(0.79-1.97)$ & 0.328 \\
\hline \multicolumn{5}{|l|}{ Evolution } \\
\hline Length of stay & $10.3(\mathrm{SD}: 8.6)$ & 12.9 (SD: 0.9) & - & $<0.001$ \\
\hline Prolonged LOS (LOS > 75thP) & $142(23)$ & $190(34.4)$ & $1.75(1.36-2.27)$ & $<0.001$ \\
\hline Readmission (30 days) & $83(13.5)$ & $94(17)$ & $1.32(0.96-1.82)$ & 0.089 \\
\hline ICU admission & $41(6.7)$ & $24(4.4)$ & $1.56(00.93-2.62)$ & 0.089 \\
\hline Vasopressors use & $39(6.5)$ & $70(13)$ & $2.15(1.43-3.24)$ & $<0.001$ \\
\hline NIV/IMV & $114(18.5)$ & $122(22.1)$ & $0.79(0.59-1.06)$ & 0.119 \\
\hline Empyema & $23(3.7)$ & $17(3)$ & $1.22(0.65-2.34)$ & 0.534 \\
\hline Mortality & $21(3.4)$ & $92(16.7)$ & $5.68(3.48-9.26)$ & $<0.001$ \\
\hline
\end{tabular}

COPD: chronic obstructive pulmonary disease. ICU: intensive care unit. IMV: invasive mechanical ventilation. LOS: length of stay. NIV: non-invasive ventilation. PSI: Pneumonia Severity Index. 75thP: 75 th percentile

Committee; Leon Health Area Clinical Research Ethics Committee, Ethics Committee for Clinical Research Area Health Valladolid-East Health Area Clinical Research Ethics Coordinating Committee of Andalusia; Clinic Ramon y Cajal, Madrid Clinical Research Ethics Committee and General Hospital University of Valencia Consortium Clinical Research Ethics Committee).

National reference no. 2013/8355

\section{Statistical Analysis}

The demographic and clinical characteristics, comorbidities and outcomes of patients with PSI IV-V with and without a $\mathrm{BI} \leq 90$ were compared. A bivariate analysis was made of patient characteristics according to 30-day survival.

The results are expressed as absolute numbers and percentages for categorical variables and as mean and standard deviation for continuous variables. A bivariate analysis was made to identify patient characteristics associated with PSI IV-V in patients with and without $\mathrm{BI} \leq 90$ and factors associated with mortality. Categorical variables were analysed using the chi $^{2}$ test, while continuous variables were analyzed using the Student's t test. The results were expressed as odds ratios (OR) and 95\% confidence intervals $(95 \% \mathrm{CI})$. Unadjusted odds ratios in the univariate analysis were calculated. Then, an adjusted OR (aOR) was calculated using multivariate analysis (stepwise forward) to assess the association between mortality (dependent variable) and independent variables with a value of $p<0.10$ in the univariate analysis.

Two multivariable models were constructed: Model 1 independently included the PSI and the BI, and model 2 included the PSI + BI stratified categorically.

Kaplan-Meier survival curves were constructed to compare mortality in patients with PSI IV-V with or without $\mathrm{BI} \leq 90$ and statistical significance was assessed using the Mantel-Cox $\log$ rank test.

\section{RESULTS}

The total study population was 1919 patients, of whom $61 \%$ had PSI IV-V and 40.4\% (775 cases) had a BI $\leq 90$ : the mean BI was 82.3 (27.3). Figure 1 shows the distribution of patients according to the PSI and BI.

Older age and comorbidities were significantly associated with a worse BI (Table 1). A worse BI was significantly associated with a poor CAP outcome.

Table 2 compares the characteristics of patients with PSI $\mathrm{IV}-\mathrm{V}$ with and without $\mathrm{BI} \leq 90$. Patients with PSI IV-V and 
Table 3 Patient Characteristics According to Survival

\begin{tabular}{|c|c|c|c|c|}
\hline & Survivors $(\mathrm{n}=1773)$ & Death $(n=146)$ & Unadjusted OR 95\% CI & P value \\
\hline \multicolumn{5}{|l|}{ Demographics } \\
\hline Mean age & 78.6 (SD: 7.3) & 82.4 (SD: 7.8) & - & $<0.001$ \\
\hline Males & $1070(6.9)$ & $88(60.3)$ & $0.98(0.69-1.34)$ & 0.890 \\
\hline Social support (lives alone) & $323(18.2)$ & $21(14.4)$ & $0.75(0.47-1.22)$ & 0.246 \\
\hline \multicolumn{5}{|l|}{ Comorbid conditions } \\
\hline Smoking & $153(8.6)$ & $15(10.3)$ & $1.21(0.69-2.12)$ & 0.499 \\
\hline Alcohol abuse & $352(19.9)$ & $21(14.4)$ & $0.68(0.42-1.09)$ & 0.108 \\
\hline COPD & $554(31.2)$ & $34(23.3)$ & $0.67(0.45-0.99)$ & 0.045 \\
\hline Diabetes mellitus & $596(33.6)$ & 49 (33.6) & $0.99(0.69-1.43)$ & 0.989 \\
\hline Chronic renal failure & $353(19.9)$ & $42(28.8)$ & $1.62(1.12-2.37)$ & 0.011 \\
\hline Malignancy & $297(16.8)$ & $40(27.4)$ & $1.87(1.28-2.76)$ & 0.001 \\
\hline Chronic liver disease & $66(3.7)$ & $9(6.29$ & $1.69(0.83-3.48)$ & 0.143 \\
\hline Cerebrovascular disease & $135(7.6)$ & $23(15.8)$ & $2.27(1.41-3.67)$ & 0.001 \\
\hline Dementia & $188(10.6)$ & $41(28.1)$ & $3.29(2.23-4.87)$ & $<0.001$ \\
\hline Chronic heart disease & $476(26.8)$ & $55(37.7)$ & $1.65(1.16-2.34)$ & 0.005 \\
\hline Immunosuppression & $159(9)$ & $16(11)$ & $1.25(0.73-2.15)$ & 0.422 \\
\hline Influenza vaccination & $931(52.5)$ & $83(56.8)$ & $1.19(0.85-1.68)$ & 0.313 \\
\hline Pneumococcal vaccination & $929(52.4)$ & $62(42.5)$ & $1.49(1.06-2.09)$ & 0.021 \\
\hline \multicolumn{5}{|l|}{ Clinical data } \\
\hline Duration of symptoms & 5.7 (SD: 9.9) & 5.4 (SD: 6.3) & - & 0.680 \\
\hline PSI IV-V & $1056(59.6)$ & $133(77.4)$ & $2.32(1.56-3.47)$ & $<0.001$ \\
\hline Barthel $\leq 90$ & $667(37.6)$ & $108(74)$ & $4.71(3.22-6.91)$ & $<0.001$ \\
\hline PSI IV $-\bar{V}+$ BI $\leq 90$ & $444(25)$ & 108 (73.9) & $4.71(3.22-6.91)$ & $<0.001$ \\
\hline \multicolumn{5}{|l|}{ Microbiology } \\
\hline Etiologic diagnosis & $442(24.9)$ & $31(21.2)$ & $0.81(0.54-1.22)$ & 0.319 \\
\hline Pneumococcal etiology & $285(21.1)$ & $13(13.1)$ & $0.57(0.31-1.03)$ & 0.059 \\
\hline Bacteremia & $101(11.2)$ & $12(13.2)$ & $1.20(0.63-2.28)$ & 0.574 \\
\hline \multicolumn{5}{|l|}{ Evolution } \\
\hline Length of stay & 10.5 (SD: 9.9) & 11.3 (SD: 7) & - & 0.348 \\
\hline Prolonged LOS (LOS $>75$ thP) & $421(23.7)$ & $49(33.6)$ & $1.62(1.13-2.33)$ & 0.008 \\
\hline Readmission (30 days) & 238 (13.4) & $26(17.8)$ & $1.39(0.90-2.18)$ & 0.139 \\
\hline ICU admission & $67(3.8)$ & $14(9.6)$ & $2.70(1.48-4.93)$ & 0.001 \\
\hline Vasopressors use & $117(6.6)$ & $23(15.8)$ & $2.65(1.63-4.29)$ & $<0.001$ \\
\hline NIV/IMV & $282(15.9)$ & $34(23.2)$ & $0.78(0.17-3.62)$ & 0.754 \\
\hline Empyema & $44(2.5)$ & $4(2.7)$ & $0.89(0.32-2.51)$ & 0.825 \\
\hline
\end{tabular}

BI: Barthel Index. COPD: chronic obstructive pulmonary disease.ICU: intensive care unit. IMV: invasive mechanical ventilation. LOS: length of stay. NIV: non-invasive ventilation. PSI: Pneumonia Severity Index. 75thP: 75th percentile

$\mathrm{BI} \leq 90$ were older, had significantly more comorbidities and had a more unfavorable evolution with more complications and greater mortality.

\section{Evolution}

The 75th percentile of mean stay was 12 days, and 264 $(13.8 \%)$ patients were readmitted within 30 days. In 140 $(7.3 \%)$ patients, vasopressors were required, and 81 patients $(4.6 \%)$ required ICU admission, while $23(1.2 \%)$ and $15(0.8 \%)$ patients required invasive and non-invasive mechanical ventilation, respectively. Forty-eight $(2.5 \%)$ patients developed pleural empyema.

Patients with $\mathrm{BI} \leq 90$ with or without PSI IV-V had a significantly longer mean hospital stay and more frequent requirement for vasopressors than patients without $\mathrm{BI} \leq 90$ (Tables 1 and 2).

Overall mortality was $7.6 \%$ (146 patients). Factors significantly associated with increased mortality were a history of chronic renal failure, malignancy, cerebrovascular disease, dementia, chronic heart disease, PSI IV-V, BI $\leq$ 90 and the combination of the latter two factors. ICU admission and the use of vasopressors were associated with a worse outcome (Table 3 ).

\section{Evolution According to PSI and BI}

Thirty-three (4.4\%) patients with PSI I-III died compared with $12.5 \%$ (146 patients) with PSI IV-V (Fig. 1). BI $\leq 90$ was significantly associated with increased mortality in patients with PSI I-III (7.2\% vs. 3.2\%; OR 2.32, 95\% CI 1.15-4.68; $\mathrm{p}=0.016)$ and PSI IV-V (14\% vs. $3.3 \%$, OR 4.71, 95\% CI 3.22-6.91; $\mathrm{p}=<0.001)$, respectively. Figure 2 compares mortality in patients with PSI IV-V with and without $\mathrm{BI} \leq 90$ (Mantel-Cox log rank 34.733; $\mathrm{p}<0.001$ ).

\section{Multivariable Analysis}

The results of the two multivariable models are shown in Table 4 . BI $\leq 90$ was an important risk factor for mortality (aOR 3.32; 95\% CI 2.19-5.03). On the other hand, the composite index of $\mathrm{BI} \leq 90$ and PSI IV-V was the greatest risk factor for mortality (aOR 4.17; 95\% CI 2.48-7.02). Age, dementia and neoplasia were also independently associated with mortality in both models.

\section{DISCUSSION}

The results of this study show that, in a cohort of noninstitutionalized patients aged $\geq 65$ years hospitalized for 


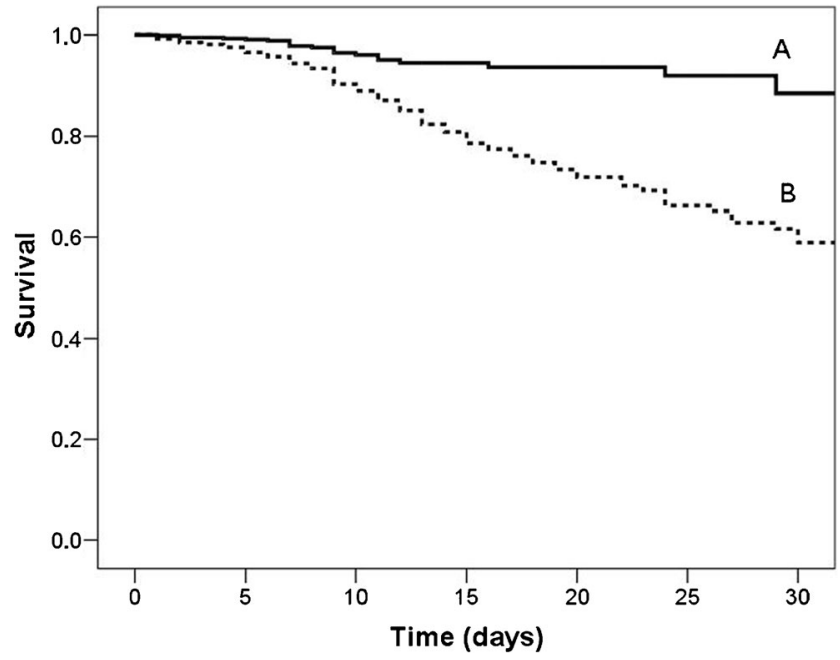

Figure 2 Kaplan-Meier survival curves by severity and functional status in patients with severe pneumonia: (A) severe pneumonia (PSI IV-V) and Barthel Index > 90 points; (B) severe pneumonia (PSI IV-V) and Barthel Index $\leq 90$ points $(p<0.001)$.

CAP, the combination of the BI and PSI improved the prediction of mortality. Other factors independently associated with mortality were older age, active neoplasm and dementia.

Accurate recognition of severity is essential for the management of pneumonia since therapeutic decision-making with the introduction of more or less intensive support measures or their interruption depends on it. ${ }^{23}$ However, the exclusive use of pneumonia severity scales results in a loss of prognostic information as it does not take into account the baseline functional status, which has been shown to be a determinant of mortality, especially in the elderly.

Assessment of the functional status using the BI has been shown to be an independent predictor of mortality in several studies with heterogeneous populations. In patients attending the ER for fever with different infectious foci, a worse baseline $\mathrm{BI}$ was associated with greater mortality. ${ }^{24}$ Studies of primarily institutionalized patients have reported that a low BI is associated not only with increased risk of nursing homeacquired pneumonia, but also with increased mortality. ${ }^{25} \mathrm{~A}$

Table 4 Multivariate Analysis of Factors Associated with Mortality

\begin{tabular}{lcc}
\hline \hline & aOR 95\% CI & p \\
\hline Model 1a: Including Barthel Index $\leq 90$ & \\
Barthel $\leq$ 90 & $3.32(2.19-5.03)$ & $<0.001$ \\
Malignancy & $2.17(1.45-3.24)$ & $<0.001$ \\
Dementia & $1.94(1.28-2.95)$ & 0.002 \\
Age & $1.05(1.02-1.07)$ & 0.001 \\
Model 1b: Including Pneumonia Severity Index (PSI) grade IV-V \\
Dementia & $2.64(1.75-3.98)$ & $<0.001$ \\
Malignancy & $2.03(1.36-3.03)$ & 0.001 \\
Chronic heart disease & $1.45(1.01-2.08)$ & 0.044 \\
PSI IV-V & $1.56(1.03-1.08)$ & $<0.001$ \\
Age & $1.06(1.03-2.38)$ & 0.038 \\
Model 2: Pneumonia Severity Index (PSI) grade IV-V plus Barthel \\
Index $\leq 90$ & & \\
PSI IV-V + Barthel $\leq 90$ & $4.17(2.48-7.02)$ & $<0.001$ \\
Dementia & $1.99(1.25-3.18)$ & 0.004 \\
Malignancy & $1.77(1.09-2.85)$ & 0.020 \\
Age & $1.04(1.01-1.07)$ & 0.007 \\
\hline
\end{tabular}

prospective observational study of factors other than the PSI associated with pneumonia mortality found a BI $<80$ was more important than other factors, such as age or comorbidities, and as important as the PSI in predicting the prognosis of elderly patients with pneumonia. ${ }^{19}$ This is particularly relevant in the case of institutionalized patients, in whom a low BI is a major determinant of the need for hospitalization. ${ }^{26}$ Furthermore, in patients aged $>75$ years with CAP, a high level of autonomy determined by the $\mathrm{BI}$ has been reported as a protective factor against mortality. ${ }^{27,28}$

An interesting point of our study is that, as shown in Fig. 2, the difference in mortality appeared to be largely after the 15th day. This is probably more related to the destabilization of comorbidities and the functional basal status rather than to the initial infectious process, in which mortality occurs earlier. The BI may be able to detect this better than the PSI. This increased mortality after 15 days may be due to the short- and long-term cardiovascular mortality previously described in relation to pneumonia. ${ }^{29,30}$

A prospective, multicenter study by Marrie et al. analyzed factors associated with mortality in patients hospitalized for pneumonia and found that a worse functional status evaluated by autonomy of movement was independently associated with reduced survival. ${ }^{31}$

Therefore, the question arises as to whether combining these indices would increase the predictive ability of pneumonia mortality in the elderly.

Despite the evidence on the influence of the functional status in the prognosis of pneumonia, there are few reports on the combined use of scales measuring functional status and the prognosis of pneumonia. Yeon et al. proposed the combined use of pneumonia risk scales (PSI, CURB-65) and the ECOG scale (Eastern Cooperative Oncology Group), which evaluates the quality of life and autonomy, and found the combination of indices improved predictions of mortality in patients with pneumonia. ${ }^{32,33}$ However, these studies have some limitations: several reports were based on very elderly patients (> 75 years) or patients living in nursing homes or long-term care facilities and with little baseline autonomy. ${ }^{28,34}$ The assessment of the functional status was made using scales designed for other patients (e.g., cancer patients) or only assessed the degree of mobility.

A strength of our study is that we collected data prospectively from a large number of patients, thus minimizing information bias. We used the BI, which is widely validated for the assessment of the functional status, unlike other studies that applied scales designed for cancer patients. ${ }^{33}$ Furthermore, use of a strict cutoff value of 90 points for BI to define some dependence allows us to demonstrate how slight changes in functional basal status can have an impact on the prognosis of pneumonia at the same initial level of severity measured by PSI, and a wider cutoff point could further increase the predictive capacity of the combined model.

The study had some limitations. We did not include institutionalized elderly patients and therefore the results may not 
be applicable to this population, nor can the results be generalized to patients aged $\leq 64$ years, who were excluded. Another potential limitation of our study is that we found significantly more dementia (23.6\%) and cerebrovascular disease $(15.4 \%)$ in the $\mathrm{BI} \leq 90$ group. Both entities are potentially associated with aspiration pneumonia, which was not assessed in our study. We recognize that the realization of BI at the time of acute illness could be affected by possible recall bias. However, we believe that recall bias would be higher for lower scores, which is why we chose to use a cutoff of 90 points.

Despite the limitations of dichotomizing quantitative scales such as the PSI and BI, this approach gives to the clinician a simple and easy tool with important prognostic information.

A potential limitation may be the time to perform BI. However, this essay takes about 5 min to complete, and there are several helpful computer tools that may be used to perform the BI.

We propose that the first assessment to be performed in a patient over 65 years of age diagnosed with community pneumonia is BI and second PSI to establish a holistic and more accurate severity assessment, which should alert the clinician to potential unfavorable outcomes and complications.

In conclusion, a combined assessment using the pneumonia severity scale and Barthel Index more accurately predicted mortality than the application of each tool separately. Future studies are needed to validate our data in different populations.

\section{Acknowledgements:}

The members of the Project PI12/02079 Working Group are: Andalusia: J.M. Mayoral (Servicio de Vigilancia de Andalucía), J. DíazBorrego (Servicio Andaluz de Salud), A. Morillo (Hospital Universitario Virgen del Rocío), M.J. Pérez-Lozano (Hospital Universitario Virgen de Valme), J. Gutiérrez (Hospital Universitario Puerta del Mar), M. PérezRuiz, M.A. Fernández-Sierra (Complejo Hospitalario Universitario de Granada). Castile and Leon: S. Tamames (Dir. General de Salud Pública, Investigación, Desarrollo e Innovación, Junta de Castilla y León), S. Rojo-Rello (Hospital Clínico Universitario de Valladolid), R. Ortiz de Lejarazu (Universidad de Valladolid), M.I. Fernández-Natal (Complejo Asistencial Universitario de León), T. Fernández-Villa (GIIGAS-Grupo de Investigación en Interacción Gen-Ambiente y Salud, Universidad de León), A. Pueyo (Hospital Universitario de Burgos), V. Martin (Universidad de León; CIBERESP). Catalonia: A. Vilella (Hospital Clínic), M. Campins, A. Antón (Hospital Universitari Vall d'Hebron; Universitat Autónoma de Barcelona), G. Navarro (Corporació Sanitària i Universitaria Parc Tauli), M. Riera (Hospital Universitari MútuaTerrassa), E. Espejo (Hospital de Terrassa), M.D. Mas, R. Pérez (ALTHAIA, Xarxa Hospitalaria de Manresa), J.A. Cayla, C. Rius (Agència de Salut Pública de Barcelona; CIBERESP), P. Godoy (Agència de Salut Pública de Catalunya; Institut de Recerca Biomèdica de Lleida, Universitat de Lleida; CIBERESP), N. Torner (Agència de Salut Pública de Catalunya; Universitat de Barcelona; CIBERESP), C. Izquierdo, R. Torra (Agència de Salut Pública de Catalunya), L. Force (Hospital de Mataró), A. Domínguez, N. Soldevila, D. Toledo, I. Crespo (Universitat de Barcelona; CIBERESP). Madrid: J. Astray, M.F. Domínguez-Berjon, M.A. Gutiérrez, S. Jiménez, E. Gil, F. Martín, R.Génova-Maleras (Consejería de Sanidad), M.C. Prados, F. Enzzine de Blas, M.A. Salvador, J. Rodríguez, M. Romero (Hospital Universitario la Paz), J.C Galán, E. Navas, L. Rodríguez-Rojas (Hospital Ramón y Cajal), C.J. Álvarez, E. Banderas, S. Fernández (Hospital Universitario 12 de Octubre). Navarra: J. Chamorro (Complejo Hospitalario de Navarra), I. Casado, J. Díaz (Instituto de Salud Pública, Instituto de Investigación Sanitaria de Navarra; CIBERESP), J. Castilla (Instituto de Salud Pública, Instituto de Investigación Sanitaria de Navarra; CIBERESP). The Basque Country: M. Egurrola,
M.J. López de Goicoechea (Hospital de Galdakao). Valencia Community: M. Morales-Suárez-Varela (Universidad de Valencia; CIBERESP), F. Sanz (Consorci Hospital General Universitari de Valencia).

Prior presentations: This work has not been presented in any meeting or conference.

Corresponding Author: Francisco Sanz, MD, PhD; Consorci Hospital General Universitari de València, València, Spain (e-mail: sanz fraher@gva.es).

Author Contributions Substantial contributions to conception or design of the work: FS, MM, EF, LF, MJP, VM, ME, JC, JA, DT, AD. Substantial contributions to the acquisition, analysis, and interpretation of data for the work: FS and EF. Drafting of the work or revising it critically for important intellectual content: FS, MM, EF, LF, MJP, VM, $M E, J C, J A, D T, A D$. Final approval of the version to be published: FS, $M M, E F, L F, M J P, V M, M E$, JC, JA, DT, AD. Agreement to be accountable for all aspects of the work in ensuring that questions related to the accuracy or integrity of any part of the work are appropriately investigated and resolved: FS, MM, EF, LF, MJP, VM, $M E, J C, J A, D T, A D$

Funders This study was funded by the National Plan of $I+D+I 2008$ 2011 and ISCIII-Subdirección General de Evaluación y Fomento de la Investigación (Project PI12/02079) and co-funded by Fondo Europeo de Desarrollo Regional (FEDER) and the Catalan Agency for the Management of Grants for University Research (AGAUR grant no. 2014/ SGR 1403).

The funders had no role in study design, data collection and analysis, decision to publish, or preparation of the manuscript.

\section{Compliance with Ethical Standards:}

Conflict of Interest: The authors declare that they do not have a conflict of interest.

\section{REFERENCES}

1. Capelastegui A, España PP, Bilbao A, et al. Poblational Study of Pneumonia (PSoP) Group. Study of community-acquired pneumonia: incidence, patterns of care, and outcomes in primary and hospital care. J Infect. 2010;61:364-71.

2. Kaplan V, Angus DC, Griffin MF, et al. Hospitalized Communityacquired pneumonia in the elderly: age and sex-related patterns of care and outcome in the United States. Am J Respir Crit Care Med. 2002;165: 766-772.

3. Kothe H, Bauer T, Marre R, Suttorp N, Welte T, Dalhoff K; Competence Network for Community-Acquired Pneumonia study group. Outcome of community-acquired pneumonia: influence of age, residence status and antimicrobial treatment. Eur Respir J. 2008;32:139-46.

4. Spoorenberg SM, Bos WJ, Heijligenberg R, et al. Microbial aetiology, outcomes, and costs of hospitalisation for community-acquired pneumonia; an observational analysis. BMC Infect Dis. 2014;14:335.

5. Fine MJ, Auble TE, Yealy DM, et al. A prediction rule to identify low-risk patients with community-acquired pneumonia. N Engl J Med. 1997;3364:243-50.

6. Lim W, van der Eerden MM, Laing R, et al. Defining communityacquired pneumonia severity on presentation to hospital: an international derivation and validation study. Thorax. 2003;58(5):377-382.

7. Marrie TJ. Community-acquired pneumonia in the elderly. Clin Infect Dis. 2000;31:1066-78.

8. Cabré M, Serra-Prat M, Force L, Palomera E, Pallarés R. Functional status as a risk factor for mortality in very elderly patients with pneumonia. Med Clin (Barc). 2008;131:167-70.

9. Ma HM, Tang WH, Woo J. Predictors of in-hospital mortality of older patients admitted for community-acquired pneumonia. Age Ageing. 2011;40:736-41.

10. Briggs R, Coughlan T, Collins R, O'Neill D, Kennelly SP. Nursing home residents attending the emergency department: clinical characteristics and outcomes. QJM. 2013;106:803-8. 
11. Brito V, Niederman MS. Predicting mortality in the elderly with community-acquired pneumonia: should we design a new car or set a new 'speed limit'?. Thorax. 2010;65:944-5.

12. Zalacain $\mathbf{R}$, Torres A, Celis $\mathbf{R}$, et al; Pneumonia in the elderly working group, Area de Tuberculosis e Infecciones Respiratorias. Communityacquired pneumonia in the elderly: Spanish multicentre study. Eur Respir J. 2003;21(2):294-302.

13. Chong CP, Street PR. Pneumonia in the elderly: a review of severity assessment, prognosis, mortality, prevention, and treatment. South Med J. 2008;101:1134-40.

14. Ewig S, Welte T, Chastre J, Torres A. Rethinking the concepts of community-acquired and health-care-associated pneumonia. Lancet Infect Dis. 2010;10:279-87.

15. Chan TC, Hung IF, Luk JK, et al. Functional status of older nursing home residents can affect the efficacy of influenza vaccination. J Gerontol A BiolSci Med Sci. 2013 ;68:324-30.

16. de Morton NA, Keating JL, Davidson M. Rasch analysis of the Barthel Index in the assessment of hospitalized older patients after admission for an acute medical condition. Arch Phys Med Rehabil. 2008;89:641-7.

17. Uematsu H, Kunisawa S, Yamashita K, Imanaka Y. The impact of patient profiles and procedures on hospitalization costs through length of stay in community-acquired pneumonia patients based on a Japanese administrative database. PLoS One. 2015;10: e0125284.

18. Matzen LE, Jepsen DB, Ryg J, Masud T. Functional level at admission is a predictor of survival in older patients admitted to an acute geriatric unit. BMC Geriatr. 2012;12:32.

19. Murcia J, Llorens P, Sánchez-Payá J, et al. Functional status determined by Barthel Index predicts community-acquired pneumonia mortality in general population. J Infect. 2010;61:458-64.

20. Mody L, Sun R, Bradley SF. Assessment of pneumonia in older adults: effect of functional status. J Am Geriatr Soc. 2006;54:1062-7.

21. Lim WS, Baudouin SV, George RC, et al. Pneumonia Guidelines Committee of the BTS Standards of Care Committee. BTS guidelines for the management of community-acquired pneumonia in adults: update 2009. Thorax. 2009; 64(Suppl. 3): iii1-55.

22. Mahoney FI, Barthel DW. Functional evaluation: the Barthel Index. Md Med J. 1965;14: 61-65.
23. Kolditz M, Ewig S, Klapdor B, et al; CAPNETZ study group. Community-acquired pneumonia as medical emergency: predictors of early deterioration. Thorax. 2015;70(6):551-8.

24. Yalcinli S, Ersel M, Karbek Akarca F,Can O, Midik S. Can Barthel Index predict mortality in geriatric patients admitted to the emergency department with a high fever? Turk J Geriatr. 2015;18(4):266-272.

25. Shiao CC, Hsu HC, Chen IL, et al. Lower Barthel Index is associated with higher risk of hospitalization-requiring pneumonia in long-term care facilities. Tohoku J Exp Med. 2015;236:281-8.

26. Dhawan N, Pandya N, Khalili M, et al. Predictors of mortality for nursing home-acquired pneumonia: a systematic review. Biomed Res Int. 2015;2015:285983.

27. Torres OH, Muñoz J, Ruiz D, et al. Outcome predictors of pneumonia in elderly patients: importance of functional assessment. J Am Geriatr Soc. 2004;52:1603-9.

28. Calle A, Márquez MA, Arellano M, Pérez LM, Pi-Figueras M, Miralles R. Geriatric assessment and prognostic factors of mortality in very elderly patients with community-acquired pneumonia. Arch Bronconeumol.2014;50:429-34.

29. Corrales-Medina VF, Alvarez KN, Weissfeld LA et al. Association between hospitalization for pneumonia and subsequent risk of cardiovascular disease. JAMA 2015; 313(3):264-274.

30. Violi F, Cangemi R, Falcone M, et al. Cardiovascular complications and short-term mortality risk in community-acquired pneumonia. Clin Infect Dis 2017;64: 1486-1493.

31. Marrie TJ, Wu L. Factors influencing in-hospital mortality in community-acquired pneumonia: a prospective study of patients not initially admitted to the ICU. Chest. 2005;127:1260-70.

32. Oken $\mathbf{M}$, Creech $\mathbf{R}$, Tormey $\mathbf{D}$, et al. Toxicity and response criteria of the Eastern Cooperative Oncology Group. Am J Clin Oncol. 1982;5:649-655.

33. Yeon Lee S, Cha SI, Seo $\mathbf{H}$, et al. Multimarker prognostication for hospitalized patients with community-acquired pneumonia. Intern Med. 2016;55:887-93.

34. Wójkowska-Mach J, Gryglewska B, Romaniszyn D, et al. Age and other risk factors of pneumonia among residents of Polish long-term care facilities. Int J Infect Dis. 2013;17:e37-43. 